\title{
Correction to: Indoxyl sulfate enhances endothelin-1-induced contraction via impairment of NO/cGMP signaling in rat aorta
}

\author{
Takayuki Matsumoto $^{1} \cdot$ Keisuke Takayanagi $^{1} \cdot$ Mihoka Kojima $^{1} \cdot$ Kumiko Taguchi $^{1} \cdot$ Tsuneo Kobayashi $^{1}$
}

Published online: 17 June 2021

๑) Springer-Verlag GmbH Germany, part of Springer Nature 2021

Correction to: Pflügers Archiv-European Journal of Physiology (2021)

https://doi.org/10.1007/s00424-021-02581-8

The order of the figures was incorrectly presented during online publication and the data of Fig. $5 \mathrm{c}$ in Table 1 was deleted during processing. This is now updated.

The original article has been corrected.

Publisher's Note Springer Nature remains neutral with regard to jurisdictional claims in published maps and institutional affiliations.

The original article can be found online at https://doi.org/10.1007/ s00424-021-02581-8.

Takayuki Matsumoto

t-matsu@hoshi.ac.jp

$\triangle$ Tsuneo Kobayashi

tkoba@hoshi.ac.jp

1 Department of Physiology and Morphology, Institute

of Medicinal, Chemistry, Hoshi University, Shinagawa-ku,

Tokyo 142-8501, Japan 